\title{
Miscanthus $x$ giganteus as a Source Of Biobased Products Through Organosolv Fractionation: A Mini Review
}

\author{
Juan José Villaverde ${ }^{1,2}$, Pablo Ligero ${ }^{1}$ and Alberto de Vega ${ }^{1}$. \\ ${ }^{1}$ Department of Physical Chemistry and Chemical Engineering, University of A Coruña, A Coruña 15071, Spain; \\ ${ }^{2}$ Present address: CICECO and Department of Chemistry, University of Aveiro, Aveiro 3810-193, Portugal
}

\begin{abstract}
This paper deals with the chemical treatments with selected organic compounds that have been applied to Miscanthus to upgrade it, for pulp production or fractionation purposes. Organosolv processes have demonstrated their effectiveness as fractionation treatments; therefore special emphasis is placed on these systems and, in particular, those making use of carboxylic acids. That is, Acetosolv process that uses acetic acid-water-hydrochloric acid mixtures as delignifying agents, the process with formic acid-water-hydrochloric acid and the Milox process, which replaces the hydrochloric acid in the medium by hydrogen peroxide, thus forming peroxyacetic acid. Furthermore, we present the results of the characterizations that have been made in relation to extractives and lignin of Miscanthus. It also is analyzed the major changes undergone by lignin during organosolv treatments. Finally, some progresses in the field of TCF bleaching of the cellulose pulps obtained are summarized.
\end{abstract}

Keywords: Miscanthus x giganteus, fractionation, organosolv, TCF bleaching, characterization.

\section{INTRODUCTION}

Miscanthus is a genus that comprises about 15 species of perennial grasses. These plants are native to tropical and subtropical regions of Africa and South Asia, and even temperate zones of Asia. Miscanthus belong to the family of Poaceae and was first described by Andersson [1]. Miscanthus are nonwood rhizomatous $\mathrm{C} 4$ perennial grasses which have an estimated productive life of at least 10-15 years. Miscanthus $x$ giganteus is a sterile hybrid between Miscanthus sinensis and Miscanthus sacchariflorus that can grow to heights more than $3.5 \mathrm{~m}$ in one single growth season. This, coupled with a high density of shoots, leads to a very high production values per year $(\approx 25 \mathrm{t} / \mathrm{ha})$, depending on the bioclimatic location. The typical harvest season is when senescence occurred, in later winter, coinciding with low moisture content $(15-20 \%)$. The high productivity is due to its $\mathrm{C} 4$ photosynthetic metabolism, identical to that of other tropical plants such as corn, sugar cane or sorghum. Thanks to this metabolism, the plant optimizes the absorption of carbon dioxide and its subsequent transformation into organic matter, also shown greater efficiency in light, water and nitrogen use than other $\mathrm{C} 3$ plants.

Many research lines worldwide have shown their interest to establish crops and develop applications for this plant in accordance with the characteristics above outlined along with other no less interesting, such as: the achievement of annual harvests that provide regular incomes to producers, good energy balance and output/input ratios compared with

*Address correspondence to this author at the Department of Physical Chemistry and Chemical Engineering, University of A Coruña, A Coruña 15071, Spain; Tel: +34 981167000 (2034); Fax: +34 981164065;

E-mail: devega@udc.es other types of biomass, low mineral content, at a late harvest, which would improve its quality as fuel, and low susceptibility to pest and diseases.

Miscanthus is a promising non-food crop, yielding high quality lignocellulosic material which may be used in a wide variety of applications as: thatching [2], direct energy production [3], fuels [4], fiberboard [5], fiber production [6], and cellulose derivatives [7]. Since the early 90s, this species has been studied as a possible candidate for an energy crop [8].

\section{COMPOSITION OF MISCANTHUS X GIGANTEUS}

The composition of Miscanthus varies with seasonal changes and with its bioclimatic location, therefore, although several groups have studied it varies, sometimes significantly, from one case to another [6, 9-12]. In our case, Miscanthus has been collected in late winter (March-April), once senescence has happened. The results of compositional analysis (Table 1) show a fibrous material with a proportion of lignin which is remarkable for a grass. $\alpha$-cellulose accounts for half the dry mass of Miscanthus although the measured glucan content is somewhat lower (38\%). However, the monosaccharide distribution after quantitative hydrolysis shows that the polysaccharide fraction is constituted by more than $95 \%$ for glucan and xylan. Lignin content is also high, closer to a woody material than to a grass. Therefore, Miscanthus stems can be an excellent raw material for both pulp and lignin.

By contrast, the core is considered a residue in most applications looking for the exploitation of the fibrous fraction of the plant, due to its content in extraneous components that hinder significantly different industrial operations. However, from another perspective, these components could open new 
lines of operation within the perspective of a comprehensive utilization of raw materials, as is the main idea that drives the development of biorefineries.

Table 1. Composition of Miscanthus $x$ giganteus

\begin{tabular}{|c|c|c|}
\hline \multicolumn{2}{|c|}{ Components } & Percentage (dry \\
\hline \multicolumn{2}{|l|}{ Ash } & 0.8 \\
\hline \multirow{3}{*}{ Extractives } & Ethanol/Toluene & 2.2 \\
\hline & Ethanol & 0.3 \\
\hline & Hot water & 1.6 \\
\hline \multirow{2}{*}{ Lignin } & Acid insoluble & 20.8 \\
\hline & Acid soluble & 0.9 \\
\hline \multirow{4}{*}{ Polysaccharides } & Holocellulose & 76.5 \\
\hline & $\alpha$-cellulose & 50.9 \\
\hline & $\beta$-cellulose & 11.9 \\
\hline & $\gamma$-cellulose & 10.6 \\
\hline \multirow{7}{*}{ Monosaccharides } & Arabinose & 1.1 \\
\hline & Xylose & 14.9 \\
\hline & Mannose & 0.0 \\
\hline & Galactose & 0.3 \\
\hline & Glucose & 38.0 \\
\hline & Rhamnose & 0.0 \\
\hline & Uronic acids & 1.2 \\
\hline
\end{tabular}

\section{Extractives of Miscanthus $x$ giganteus}

The lipophilic extractives of Miscanthus $x$ giganteus have been isolated and analyzed by Villaverde et al. [13]. Core and bark have a similar proportion of extractives, 0.53 and $0.63 \%$, respectively. Gas chromatrography-mass spectrometry revealed a similar distribution of compounds in both cases, but with some differences. Aromatic compounds were the predominant family accounting for roughly a third part of the extractives detected (Fig. 1). Among them, vanillic acid, vanillin, $\mathrm{p}$-hydroxybenzaldehide, and $p$-coumaric acid were, in this order, the major components. In the core, the same compounds are predominant, but the order changed: pcoumaric, vanillic acid, $p$-hydroxybenzaldehide, and vanillin. Sterols distribution in both materials was more balanced, as proportions were not as different as in previous case. However, the $\beta$-sitosterol was the predominant sterol in both cases. The distribution of fatty acids was headed by octacosanoic acid in bark, and hexadecanoic acid in core.

Given the favorable characteristics of compounds like simple phenols and sterols, Miscanthus could be a good source of these chemicals. Indeed, sterols possess properties of reducing cholesterol levels in blood serum [14], some phenolic compounds have recognized antioxidant activity used in the food industry as well as other effects of the type anti-allergic, anti-artherogenic, anti-inflammatory, antimicrobial, vasodilatant, etc. [15]. One application of this kind, not alone but as a first step in the integral utilization of the plant would help the revalorization of the raw material.

\section{Native Lignin of Miscanthus $x$ giganteus}

In order to describe the structure of native lignin, usually analyses are carried out on a few degraded form of the polymer called "Milled Wood Lignin" (MWL). A number of studies on the structural characterization of lignin from different herbaceous crops have been reported in the literature, but the first study on the determination of phenolic hydroxyl group content of milled wood lignin from Miscanthus sinensis was published by Faix [16]. Recently, more complete studies in the characterization of Miscanthus $x$ giganteus MWL were reported $[17,18]$, showing that it is highly acylated at the $\mathrm{C} \gamma$ of the side chain (46\%), possibly with $p$ coumarate and/or acetate groups [17]. This is remarkable since several earlier studies showed that acylation at the $\gamma$ carbon commonly occurs in C3- and CAM-grasses [19], whereas $M . x$ giganteus is a $\mathrm{C} 4$ grass. Furthermore, $M . x$ giganteus showed a low $\mathrm{S} / \mathrm{G}$ ratio (0.7) and a predominance of $\beta-O-4$ ' linkages (up to $93 \%$ of all linkages) [17]. Also contains a very low proportion of condensed linkages such as spirodienone $\left(\beta-1^{\prime}\right)$ (detected in a quantity lower than $0.5 \%)$, phenylcoumaran $\left(\beta-5^{\prime}\right)$ and resinol $\left(\beta-\beta^{\prime}\right)$ [17]. It is believed that the high acylation at $\mathrm{C} \gamma$ could be the reason for the low abundance of the double tetrahydrofuran ring from resinol, which requires free hydroxyls in $\mathrm{C} \gamma$ to be formed [19]. MWL from Miscanthus contained high proportions of carbohydrates $(\approx 23 \%)$, mainly composed by xylose which accounts for almost the $80 \%$ of monosaccharides, suggesting that there actually is a lignin-carbohydrate complex. On the other hand, average C9 formulae for MWL stem, calculated from the elemental composition data was $\mathrm{C}_{9} \mathrm{H}_{9.6} \mathrm{O}_{3.1}$ [18].

\section{ORGANOSOLV FRACTIONATION OF MISCANTHUS X GIGANTEUS}

\section{Organosolv with Phenol}

Studies on delignification of lignocellulosic materials with phenol started at the beginning of $20^{\text {th }}$ century. The first written reference is from a German patent in 1919 [20]. More recently, studies have been published on phenol pulping of pine and beech wood [21], the description of a fractionation process with phenol and diluted $\mathrm{HCl}$ solutions (Battelle method) [22], and the application of this method to Ulex europaus, a very common shrub in Galicia (NW of Spain) [23]. Briefly, the Battelle method is as follows: the fractionation of the raw material is achieved by the action of a liquor comprising a mixture of phenol and water with small amounts of hydrochloric acid. The acid acts in two ways: by modifying the structure of lignin by partial depolymerization until obtaining soluble fragments, and hydrolyzing the hemicellulosic fraction with the subsequent solubilization of the monosaccharides released. The phenol-water mixture that is immiscible at room temperature becomes homogeneous during heating. Typically the cooking temperature is $100^{\circ} \mathrm{C}$. After the reaction, as the temperature decreases, the mixture returns to be immiscible, separating in one organic phase (phenolic), containing the dissolved lignin, and one aqueous phase, containing the hydrolyzed monosaccharides. Use of greater pressures is not necessary because good results can be obtained at atmospheric pressure.

The organosolv treatment with phenol applied to Miscanthus has been optimized in previous works [6, 24]. The 

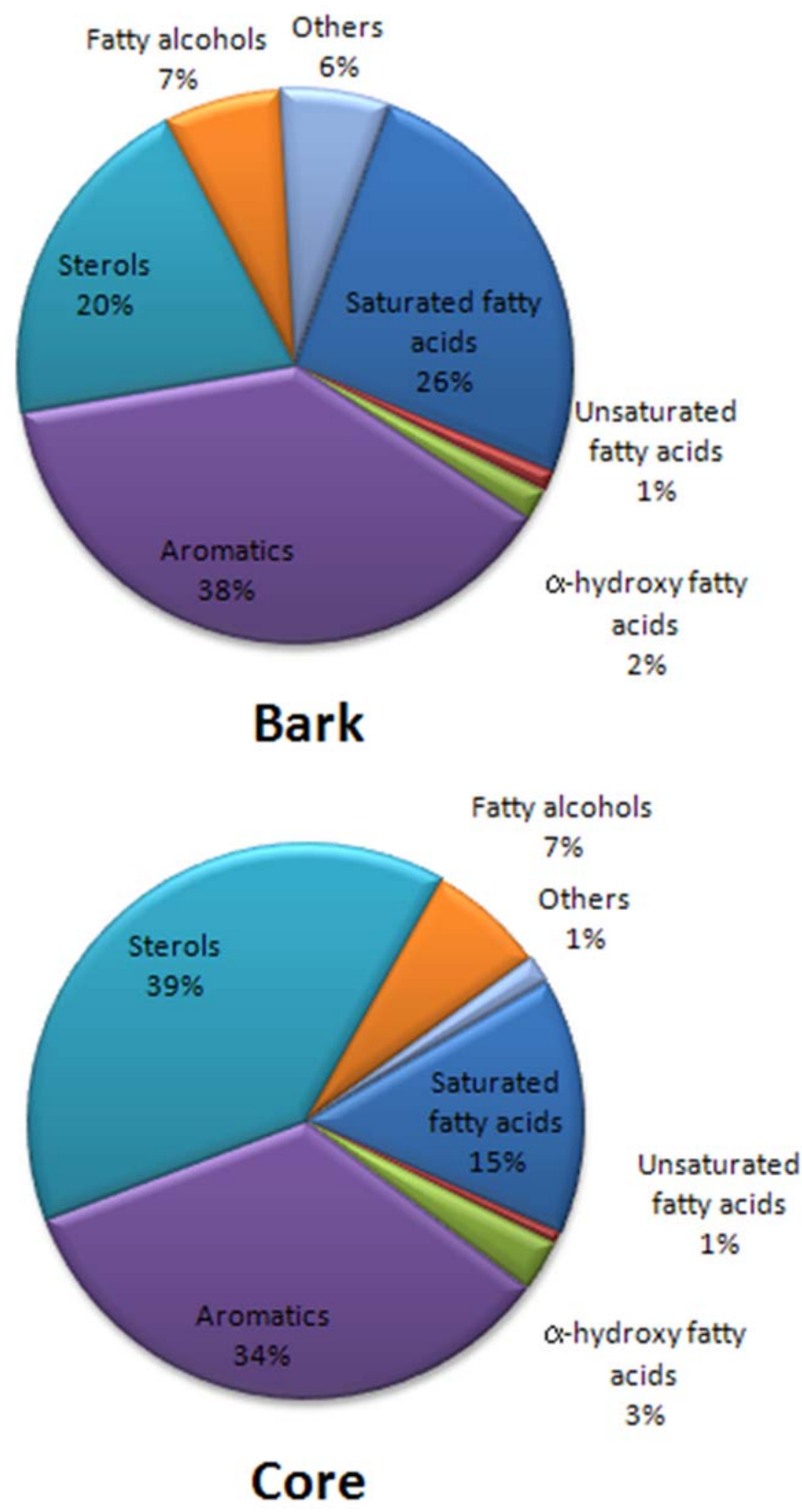

Fig. (1). Distribution of extractives in the bark and core of Miscanthus x giganteus (\% referred to identified products).

method has been proved to be valid to attain at time the prehydrolysis and delignification of the raw material, i.e. its fractionation. For this purpose, it has been shown that a high fractionation rate (measured as: solubilized mass of carbohydrates plus lignin/total mass solubilized) were reached, with values of $72 \%$, together with delignification efficiencies of $83 \%$. A representation of these results is shown in Fig. (2), where variables are normalized, that is, the intervals (-1, 1) correspond to $(0.02,0.05) \mathrm{g} \mathrm{HCl} / \mathrm{g}$ dried Miscanthus and $(45,55) \%$ weight percentage of phenol in liquor. Although this delignification may be higher, by modifying the operational variables (because the lignin content of pulp is still relatively high, $10 \%$ ), the increase is obtained at the expense of the fractionation rate, which can be detected as a significant increase especially at the content of hemicelluloses sugars in aqueous solution. This is because to the necessity of increasing the amount of $\mathrm{HCl}$ in the liquor, which involves a more significant contribution of the acid-catalyzed degradation reactions of monosaccharides.

The main advantage of this process is that the separation of the dissolved fragments of hemicelluloses and lignin occurs spontaneously due to the physical characteristics of the phases involved, thus avoiding a separation operation. Moreover, the partial depolymerization of lignin produces phenols of small molecular size [21, 22] that, as phenol itself, are good delignification agents. Therefore, in this sense, the treatment is not only self-sufficient but also produces an excess of phenols

However, the presence of phenol in the aqueous phase requires in terms of its toxicity, a subsequent removal treatment, especially if the aqueous liquor is to be used in fermentation processes. 


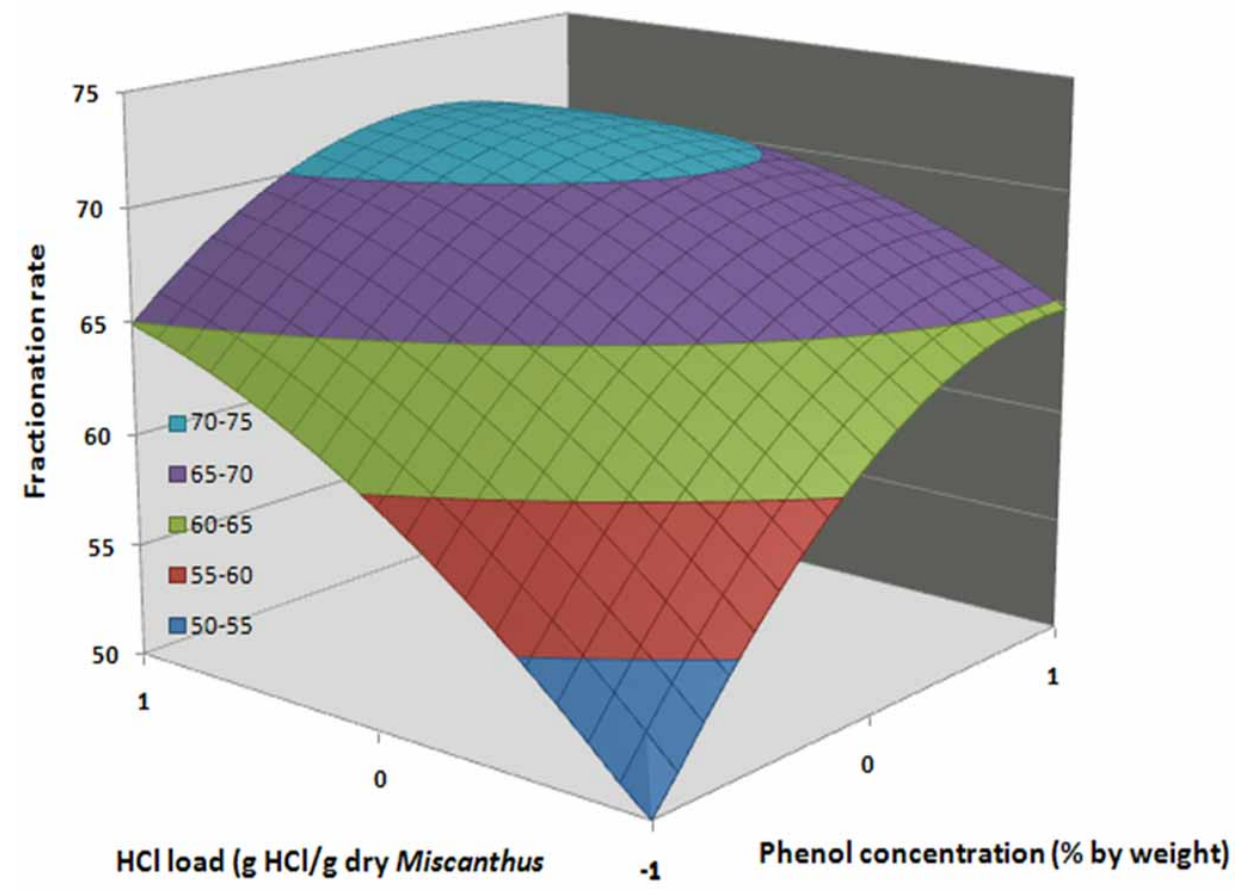

Fig. (2). Fractionation of Miscanthus in the organosolv treatment with phenol. Influence of $\mathrm{HCl}$ and phenol concentration on fractionation rate.

\section{Organosolv with Formic Acid}

Formic acid has been revealed as a high selectivity delignification agent for wood, even at very mild conditions [2527]. In a medium consisting of a mixture of formic acid, water, and small quantities of hydrochloric acid, the lignin is depolymerized, oxidized, and dissolved with most of the hemicelluloses and extractives. Subsequently, the lignin can be precipitated from the cooking liquor through an increase in pH by simply adding water. The method has been proven (in the range $80-100^{\circ} \mathrm{C}, 15-90 \mathrm{~min}$ ) in eucalyptus and pine species with good results in relation to delignification efficiency, fractionation of the raw material, and improving the saccharification rate of the raw materials. Moreover, pulps with Klason lignin contents as low as $4 \%$ have been obtained with eucalyptus sawdust.

The process with formic acid, thereafter Formosolv, applied to Miscanthus has been optimized by studying the influences of variables on several parameters of the fractionation $[28,29]$. The fractionation proceeded with a high solubilization of materials during the heating period: indeed, $30 \%$ of the initial mass dissolved during this phase (pulp yields about $70 \%$ ). From there, the reactions occurred very rapidly until approximately 20 minutes (Fig. 3): the kappa number decreased from 24 to 7 , while the pulp yield remained slightly above $50 \%$. In regard to the proportion of polysaccharides in pulp, also increased rapidly in this phase reaching values around $90 \%$, remaining there for more prolonged times $(180 \mathrm{~min})$. The viscosity of pulps reached the highest levels, close to $1200 \mathrm{~cm}^{3} / \mathrm{g}$, in just 15 minutes being, from there, the effect of $\mathrm{HCl}$ hydrolysis evident by decreasing the viscosity quite rapidly.

\section{Organosolv with Acetic Acid}

Acetic acid delignification (Acetosolv) has been firstly designed in 1986 as a pulping method for pinewood [30]. An aqueous mixture enriched in acetic acid with small amounts of hydrochloric acid is maintained under reflux at atmospheric pressure for a given time. A set of experimental conditions can be identified in order to obtain pulps with kappa numbers below 30 [30]. The process can be also operated without mineral acid (Acetocell) at comparatively high temperatures [31]. The Acetosolv system has been used to efficiently delignify softwoods [32], hardwoods [33] and nonwoody materials [34]. The mode of operation is similar to the previous method but replacing formic with acetic acid.

The Acetosolv method has been applied to Miscanthus with good delignification percentages [35]. Fig. (3) shows the evolution with time of the main parameters of the fractionation. The process proceeded in a similar manner to formic acid system but there are some significant differences. While time profiles of Klason lignin and polysaccharides remaining in pulp are very similar in both systems, the behaviour of yield and viscosity of pulps is different. Being comparable the shapes of the representation yield $v s$ process time, acetic acid system solubilises, for a given time, less mass than formic; this means that higher yields are obtained with Acetosolv treatment. But the most important difference is related with viscosity evolution. Whereas formic acid achieved the high viscosity in a few minutes, the behaviour in the Acetosolv system is notably slower. In fact, maximum viscosity was not attained until a reaction time of $120 \mathrm{~min}$ utes. Nevertheless, these maximum values were roughly the same in both organosolv processes.

\section{Organosolv with Peroxyformic Acid (Milox)}

Milox process is one of the most promising organosolv methods [36]. It is based on the action of peroxyformic acid in-situ generated by the reaction between formic acid and hydrogen peroxide. It was applied successfully on different biomass material as non-wood [36], hardwoods [37] and 


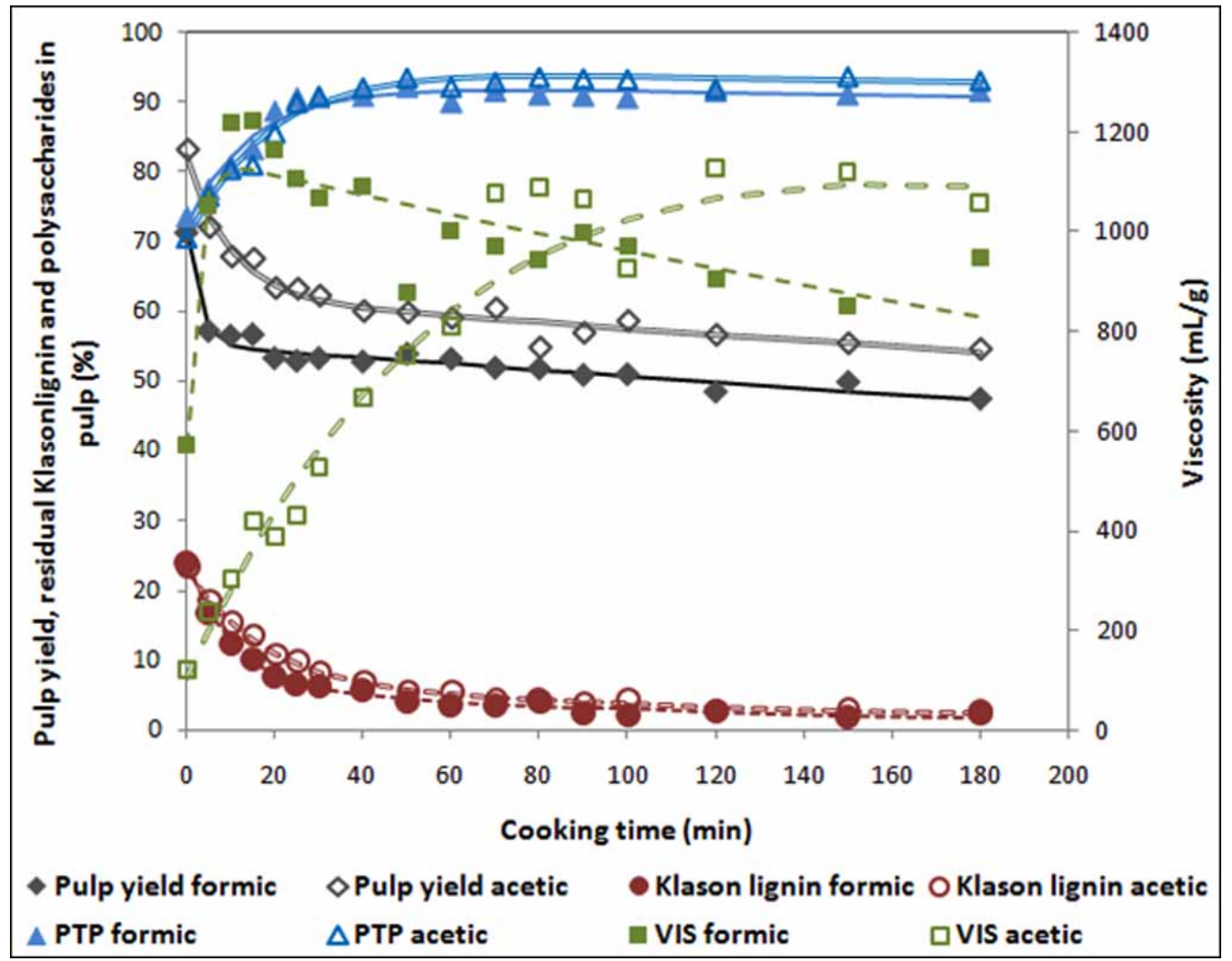

Fig. (3). Time evolution of the main parameters in the fractionation of Miscanthus with formic and acetic acid.

softwoods [38]. Typical Milox treatment involves three stages, one with carboxylic acid between other two with carboxylic acid and hydrogen peroxide. In the first stage, lignin is attacked by ${ }^{+} \mathrm{OH}$ ions, which come from in situ reaction between acid carboxylic and hydrogen peroxide. Finally, in the third stage, high molar mass lignin is removed. Nevertheless, Milox (or peroxyformic) process has been successfully used in one stage [39] or two-stage [36]. Previous works have found that two-stage Milox method is more effective for pulping of agricultural plants than the three-stage method, which is used for pulping wood species.

Milox process applied to Miscanthus affords a pulp with more brightness than that obtained in the previous processes [39]. The formation of a very powerful oxidant agent contributes not only to a more important delignification but also to a significant brightness increase. From the viewpoint of obtaining pulps with low kappa number, this is very helpful but, if it is desired preferably the fractionation of the starting material, attaining very low kappa pulps is contraindicated. The reason is double: first, there is an oxidative degradation of lignin, more important than in other processes, which transform it into compounds of very small size that cannot be precipitated, and second, cellulose is severely damaged, as it was reflected in very low values of viscosity (400-500 $\mathrm{cm}^{3} / \mathrm{g}$ ) obtained with Miscanthus when hydrogen peroxide concentrations higher than $4 \%$ were used. Furthermore, the more amount of peroxide is in the medium, the higher content of saponifiable groups is present in pulps, which is a disadvantage in the subsequent bleaching process. Therefore, being the amount of hydrogen peroxide in liquor the most important factor influencing the rate of lignin recovered by precipitation, this parameter must be carefully controlled. By doing this, balanced results between delignification and fractionation can be obtained.

When Miscanthus stems were subjected to Milox treatment under optimized conditions and controlled hydrogen peroxide concentrations, bleachable pulps (kappa numbers below 25) have been achieved. At the same time, cellulose was preserved $\left(>900 \mathrm{~cm}^{3} / \mathrm{g}\right)$, and pulp yields were very favorable $(52-55 \%)$.

\section{Organosolv lignins}

Acetosolv lignin (AcL) and Formosolv lignin (FoL) can be easily precipitated from the cooking liquor (Fig 4). A simple modification of $\mathrm{pH}$ enabled to recover an important quantity of the lignin dissolved during organosolv processes, namely about $90 \%$. The precipitation became more intense as the $\mathrm{pH}$ increased, reaching an asymptotic rate for different $\mathrm{pH}$ values. Although the maximum precipitation is obtained at different $\mathrm{pH}$, depending on the composition and hence on the ionic strength of the liquors, the behavior of the process against the dilution factor is very similar in all three cases (Fig. 5), reaching precipitation rates near $90 \%$ of the initial lignin. Therefore, for study, all lignins were precipitated using a volumetric ratio water/liquor $=6$ [17].

The changes suffered in lignin structure after Acetosolv and Formosolv treatment were investigated by Villaverde $e t$ al. [17]. As expected organosolv treatments caused important changes which were detectable by several analytical techniques. First, the lignin-carbohydrate complex was broken, which is reflected in a drastic reduction in carbohydrates: from 22\% in MWL to values around 2\% (also visible in FTIR spectra). Even the monosaccharide distribution was 


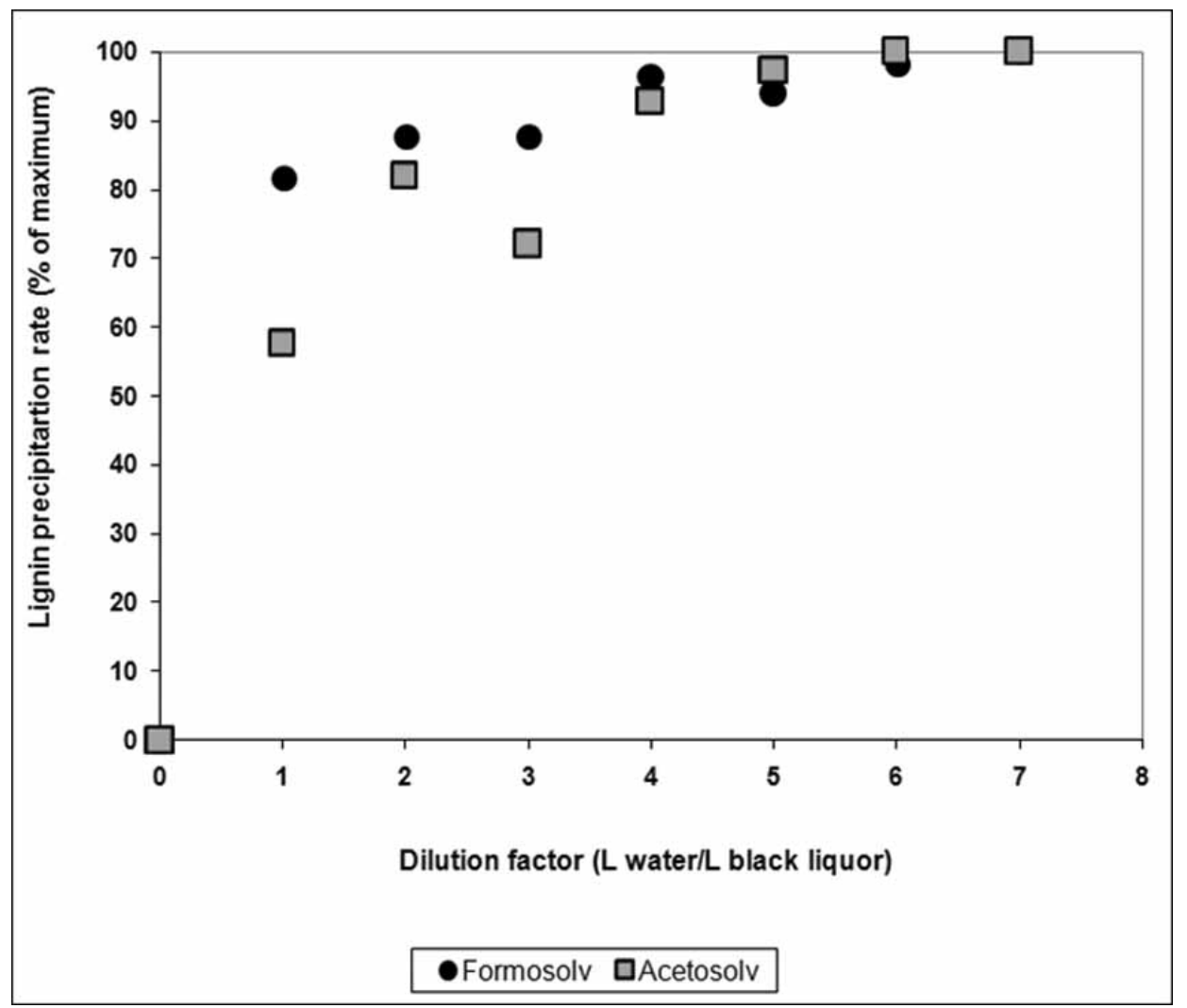

Fig. (4). Lignin precipitation profiles as a function of dilution factor in Miscanthus organosolv liquors.

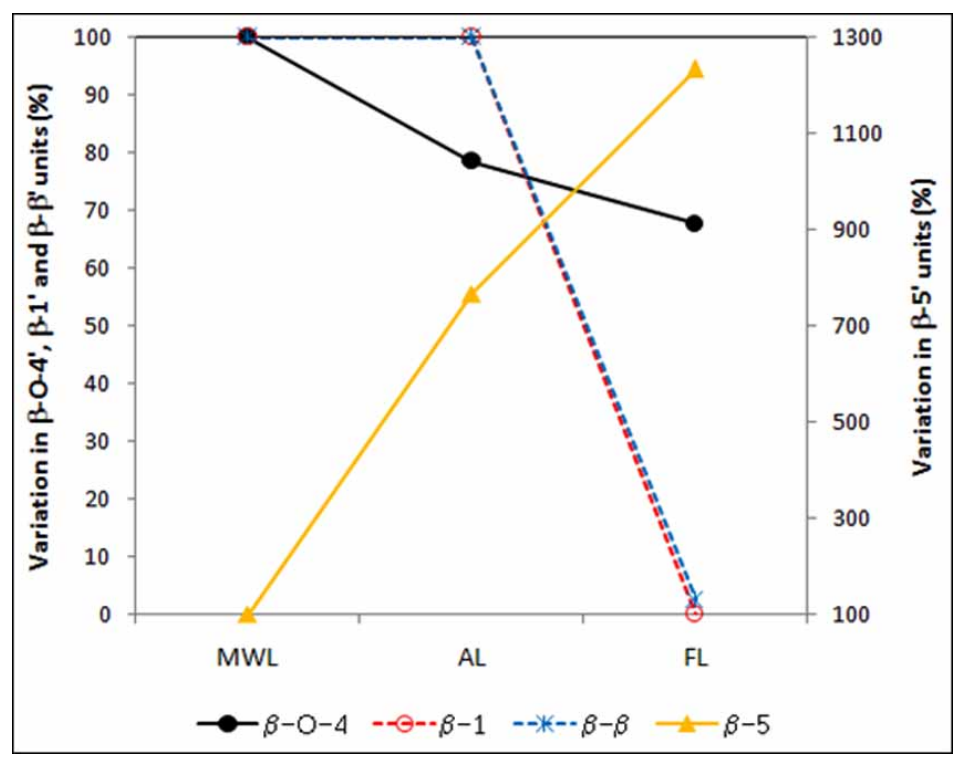

Fig. (5). Percentage changes on the contents of major structural lignin units between MWL and organosolv lignins.

modified: whereas in LCC, xylose is clearly the predominant sugar, organosolv lignins showed more similar proportions of xylose and arabinose, reflecting a higher solubilization of xylose during treatment [17].

The comparison of 2D NMR spectra of Miscanthus MWL, AcL, and FoL demonstrated considerable changes during fractionation [17]. The main is that $\beta-O-4$ ' links decreased significantly in organosolv lignins $(21.5$ and $31.6 \%$, respectively) (Fig. 5). This was also reflected in SECchromatography, which showed molecular weights of both organosolv lignins lower than that of MWL [17]. By contrast, $\beta-5$ ' linkages seem to be more resistant to these treatments, because their proportions are highly superior in AcL and FoL. Anyway, the analysis of thioacidolysis products suggests that also some extent of lignin condensation has taken place. Furthermore, significant variations were measured for the S/G ratios, whose values were increased from 0.7 in the MWL to 1.8 in AL and 2.0 in FL. These results are consistent with the idea that G-units suffered the condensation reactions to a greater extent than $\mathrm{S}$-units. 


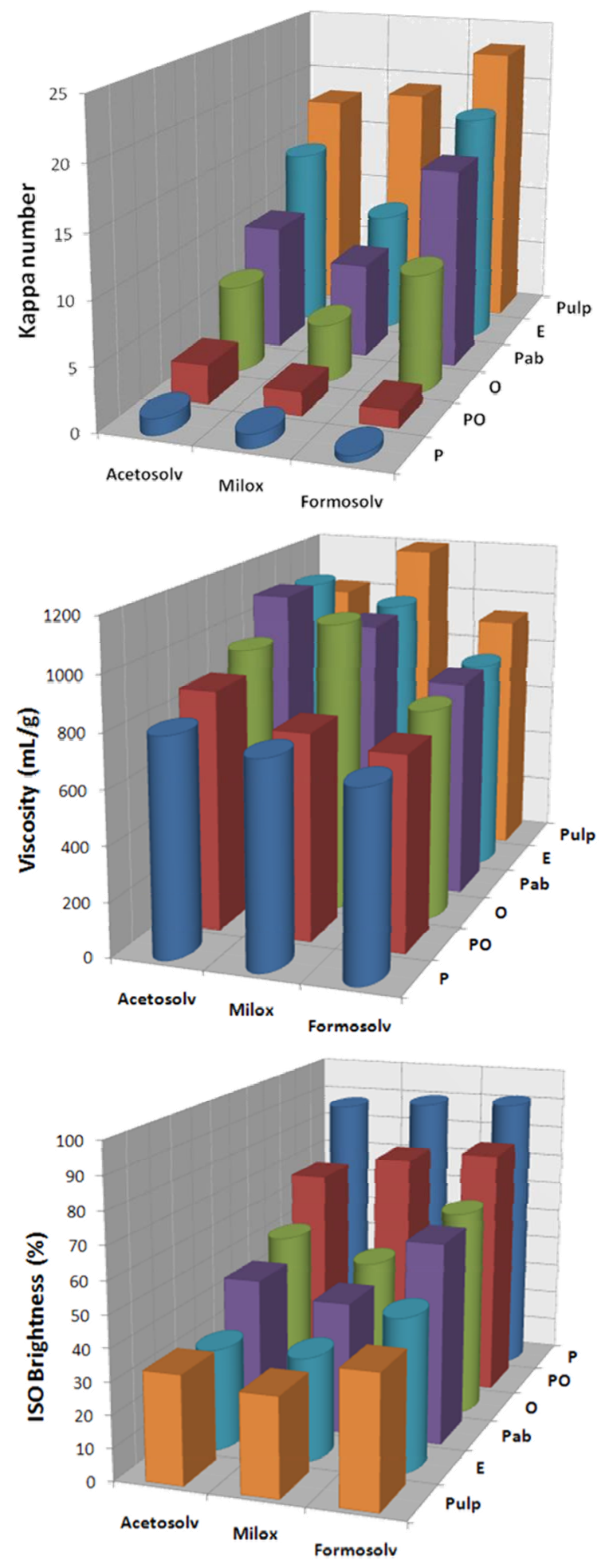

Fig. (6). Performance of the TCF sequence on kappa number, viscosity and brightness of Miscanthus organosolv pulps.

\section{Organosolv Celluloses}

The organosolv processes mentioned have been optimized for treating Miscanthus from the standpoint of fractionation; this means that while delignification obtained is quite good, in stronger conditions, one could obtain pulps with lower lignin content. In any case, the kappa numbers of pulps obtained are lower than 25 and require further bleach- ing treatments, whatever their final destination (pulp for paper, dissolving pulps). Pulps of this type fall into the category of bleachable pulps. The bleaching of cellulose pulps involves the sequential action of a well designed series of chemicals (delignifying agents and brightness improvers). Traditionally, one or more stages in these sequences used chlorine or chlorine dioxide, with the consequent formation of organochlorine compounds and the subsequent environmental impact. Currently, the best technology available for this purpose is called TCF bleaching, which simply involves the use of bleaching chemicals absolutely free of chlorine. Normally oxygen and/or oxygen compounds with high oxidizing power are used: hydrogen peroxide, ozone, peroxyacids.

Miscanthus organosolv pulps have a relatively high proportion of saponifiable groups, which requires an initial saponification stage at the beginning of the bleaching sequence. This alkaline extraction stage (stage E) has been optimized being the main effect obtained, apart from the removal of saponifiable groups, the delignification of pulp: 19\% delignification in Acetosolv and Formosolv, and almost $50 \%$ in Milox (Fig. 6). Peroxyacetic acid, a highly oxidizing compound, was used in the second stage trying to increase the brightness and continue delignification [40]. This stage was also optimized and in the best conditions delignification rates were somewhat higher than those for the increase of brightness. Meanwhile, the viscosity still remained at high levels (above 800 and $1100 \mathrm{~cm}^{3} / \mathrm{g}$ ) (Fig. 6).

For the third stage a treatment under pressurized oxygen (O-stage) was chosen with the aim of producing a very significant delignification [41]. Nevertheless, this stage produced delignification and brightness increase at almost the same percentage, being more effective with Milox pulps (Fig. 6).

Finally, two last peroxide stages were implemented to increase brightness until the highest possible values: a peroxide oxygen pressurized stage (PO) and a simple peroxide stage $(\mathrm{P})[41]$.

Interestingly, this two stages, designed to improve brightness over any other factor, though they do spectacularly, also contribute very significantly to the delignification, reaching kappa number values below 1.5. The brightness, in fact, suffered a very significant increase reaching values close to $90 \%$, while the viscosity is affected significantly, although remaining at very good values (above $680 \mathrm{~cm}^{3} / \mathrm{g}$ ). Anyway, it should be mentioned that in each of the above stages, the need for using chelating agents (DTPA and magnesium sulfate) to protect cellulose degradation was studied, and only in the last two stages (PO and P) were effective. Therefore, the values presented are those obtained with these substances in the bleaching liquor. Other authors have also proposed another TCF sequence, centered on the use of ozone (WA-Op-AZR-P), for pulps from an alkaline pulping treatment [42].

In summary, after the organosolv fractionation of Miscanthus, is possible to obtain fully bleached pulps by a totally chlorine-free treatment $(\mathrm{EPab}(\mathrm{PO}) \mathrm{P})$ with results comparable to those of other recognized sequences. 


\section{CONCLUSIONS}

Though introduced in Europe for energy purposes, there are proven technologies in the laboratory for the chemical processing that allow fractionation of its lignocellulosic biomass and the subsequent revalorization of the fractions separated. Without conflicting with other energy applications, but even supplementing, these treatments may be of interest to obtain high added value products: lignin and its derivatives, cellulose, dissolving pulps, etc. Organosolv processes have demonstrated sufficient effectiveness to achieve the fractionation of the raw material that, within the concept of a biorefinery, which is again revitalized in the scientific literature, may have an important role. Currently, the body of knowledge about the plant has increased significantly, and has a number of experimental works that encourage the efficient use of this species.

\section{REFERENCES}

[1] Andersson NJ. Description of Miscanthus sinensis. Öfversigt af Svenska Vetenskaps-Akademiens Förhandlingar Stockholm. 1885; 7: 165-167.

[2] Kjeldsen JB, Jørgensen U, Kristensen E.F. Miscanthus for thatching. In: Markbrug, DJF Rapport, Foulum 1999; p. 59.

[3] Wagenaar BM, Van den Heuvel EJMT. Co-combustion of Miscanthus in a pulverised coal combustor: Experiments in a droptube furnace. Biomass Bioenerg 1997; 12: 185-97.

[4] Khelfaa A, Sharypovb V, Finqueneisela G, Weber JV. Catalytic pyrolysis and gasification of Miscanthus Giganteus: Haematite $\left(\mathrm{Fe}_{2} \mathrm{O}_{3}\right)$ a versatile catalyst. J Anal Appl Pyrol 2009; 84: 84-88.

[5] Salvadó J, Velásquez JA, Ferrando F. Binderless fiberboard from steam exploded Miscanthus sinensis: optimization of pressing and pretreatment conditions. Wood Sci Technol 2003; 37: 279-286.

[6] Vega A, Bao M, Lamas J. Application of factorial design to the modelling of organosolv delignification of Miscanthus sinensis (elephant grass) with phenol and dilute acid solutions. Bioresour Technol 1997; 61: 1-7.

[7] Barba C, Montane D, Rinaudo M, Farriol X. Synthesis and characterization of carboxymethylcelluloses (CMC) from non-wood fibers I. Accessibility of cellulose fibers and CMC synthesis. Cellulose 2002; 9: 319-326.

[8] Clifton-Brown JC, Long SP, Jorgensen U. 2001. Miscanthus productivity. In: Jones MB, Walsh M, Eds. Miscanthus for Energy and Fibre. London, James \& James 2001; pp. 46-67.

[9] Faix O, Meier D, Beinhoff O. Analysis of lignocelluloses and lignins from Arundo donax L. and Miscanthus sinensis Anderss., and hydroliquefaction of Miscanthus. Biomass 1989; 18: 109-126.

[10] Iglesias G, Bao M, Lamas J, Vega A. Soda pulping of Miscanthus sinensis. Effects of operational variables on pulp yield and lignin solubilization. Bioresour Technol 1996; 58: 17-23.

[11] Marin F, Sanchez JL, Arauzo J, Fuertes R, Gonzalo A. Semichemical pulping of Miscanthus giganteus. Effect of pulping conditions on some pulp and paper properties. Bioresour Technol 2009; 100: 3933-40.

[12] de Vrije T, de Hass GG, Tan GB, Keijsers ERP, Claassen PAM. Pretreatment of Miscanthus for hydrogen production by Thermotoga elfii. Int J Hydrogen Energy 2002; 27: 1381-90.

[13] Villaverde JJ, Domingues RMA, Freire CSR, et al. Miscanthus $x$ giganteus extractives: a source of valuable phenolic compounds and sterols. J Agric Food Chem 2009; 57: 3626-31.

[14] Quilez J, Garcia-Lorda P, Salas-Salvado J. Potential uses and benefits of phytosterols in diet: Present situation and future directions. Clin Nutr 2003; 22: 343-51

[15] Balasundram N, Sundram K, Samman S. Phenolic compounds in plants and agri-industrial by-products: Antioxidant activity, occurrence, and potential uses. Food Chem 2006; 99: 191-203.

[16] Faix O, Grunwald C, Beinhoff O. Determination of phenolic hydroxyl group content of milled wood lignins (MWL's) from different botanical origins using selective aminolysis, FT-IR, proton NMR, and UV spectroscopy. Holzforschung 1992; 46: 425-32.
Villaverde JJ, Li J, Ek M, Ligero P, Vega A. Native lignin structure of Miscanthus $x$ giganteus and its changes during acetic and formic acid fractionation J Agric Food Chem 2009; 57: 6262-70.

[18] El Hage R, Brosse N, Chrusciel L, Sanchez C, Sannigrahi P, Ragauskas A. Characterization of milled wood lignin and ethanol organosolv lignin from miscanthus. Polym Degrad Stab 2009; 94: 1632-38.

[19] del Río JC, Marques G, Rencoret J, Martínez AT, Gutiérrez A. Occurrence of naturally acetylated lignin units. J Agr Food Chem 2007; 55: 5461-68.

[20] Hartmuth R. Verfahren zur Behandlung von Holz oder zellulosehaltigen Stoffen zwecks Gewinnung von Zellulose und künstlichen Harz, Lack, Asphalt u. dgl., D. Patent 328783. 1919.

[21] Schweers WH. Phenol pulping. Chemtech 1974; 4: 490-3.

[22] Sachetto JP, Armanet JM, Roman A, Johansson A. The fractionation of lignocellulosics for the production of chemicals, Paper presented at the Conf. "Degradation of lignocellulosics in ruminants and in industrial, processes". Leystad, The Netherlands, 17-20 March 1982.

[23] Vega A, Bao M. Fractionation of lignocellulosic materials with phenol and dilute $\mathrm{HCl}$. Wood Sci Technol 1991; 25: 459-466.

[24] Vega A, Bao M, Rodríguez, JL. Fractionating lignocelluloses of Miscanthus sinensis with aqueous phenol in acidic medium. Holz Roh Werkst 1997; 55: 189-94.

[25] Lam HQ, Le Bigot Y, Delmas M, Avignon G. Formic acid pulping of rice straw. Ind Crops Prod 2001; 14: 65-71

[26] Sarwar Jahan M, Nasima Chowdhury DA, Khalidul Islam M. Atmospheric formic acid pulping and TCF bleaching of dhaincha (Sesbania aculeata), kash (Saccharum spontaneum) and banana stem (Musa Cavendish). Ind Crops Prod 2007; 26: 324-31

[27] Tu Q, Fu S, Zhan H, Chai X, Lucia LA. Kinetic Modeling of Formic Acid Pulping of Bagasse. J Agric Food Chem 2008; 56: 3097101

[28] Caridad R, Ligero P, Vega A, Bao M. Formic acid delignification of Miscanthus sinensis. Cell Chem Technol 2004; 38: 235-44

[29] Villaverde JJ, Ligero P, Vega A. Formic and acetic acid as agents for a cleaner fractionation of Miscanthus x giganteus. J Clean Prod 2010; 18: 395-401.

[30] Nimz HH, Casten R. Chemical processing of lignocellulosics. Holz Roh Werks 1986; 44: 207-12.

[31] Neumann N, Balser K. Acetocell - An innovative process for pulping, totally free from sulfur and chlorine. Papier 1993; 47: 16-24.

[32] Vazquez G, Antorrena G, Gonzalez J, Freire S, Lopez S. Acetosolv pulping of pine wood. Kinetic modeling of lignin solubilization and condensation. Bioresour Technol 1997; 59: 121-7.

[33] Ligero P, Villaverde JJ, Vega A, Bao M. Delignification of Eucalyptus globulus saplings in two organosolv systems (formic and acetic acid): Preliminary analysis of dissolved lignins. Ind Crops Prod 2008; 27: 110-7.

[34] Ligero P, Villaverde JJ, Vega A, Bao M. Acetosolv delignification of depithed cardoon (Cynara cardunculus) stalks. Ind Crops Prod 2007; 25: 294-300

[35] Ligero P, Vega A, Bao M. Acetosolv delignification of Miscanthus sinensis bark Influence of process variables. Ind Crops Prod 2005; 21: 235-40.

[36] Seisto A, Poppius K. Milox pulping of agricultural plants. In, Proceedings of the $8^{\text {th }}$ International Symposium on wood and Pulping Chemistry, June 6-9, Helsinki, Finland. 1995; vol. 1: pp. 407-14.

[37] Abad S, Santos V, Parajo JC. Evaluation of Eucalyptus globulus wood processing in media made up of formic acid, water, and hydrogen peroxide for dissolving pulp production. Ind Eng Chem Res 2001; 40: 413-9.

[38] Obrocea P, Cimpoesu G. Contribution to sprucewood delignification with peroxyformic acid. I. The effect of pulping temperature and time. Cell Chem Technol 1998; 32: 517-25.

[39] Ligero P, Vega A, Bao M. Efficient delignification of Miscanthus sinensis using the Milox process. $2^{\text {nd }}$ World Conference and Technology Exhibition on Biomass for Energy, Industry and Climate Protection. 10-14 May 2004. Rome.

[40] Villaverde JJ, Ligero P, Vega A. Bleaching Miscanthus $x$ giganteus Acetosolv pulps with hydrogen peroxide/acetic acid. Part 1: Behaviour in aqueous alkaline media. Bioresour Technol 2009; 100: 4731-5.

[41] Villaverde JJ, Ligero P, Vega A. Bleaching Miscanthus $x$ giganteus Acetosolv pulps with a new totally chlorine-free sequence and the 
effect of carbohydrate protectors. Ind Eng Chem Res 2009; 48: 9830-9836.

[42] Barba C, de la Rosa A, Vidal T, Colom JF, Farriol X, Montane D.

TCF bleached pulps from Miscanthus sinensis by the impregnation rapid steam pulping (IRSP) process. J Wood Chem Technol 2002; 22: $249-266$

Received: October 30, 2009

Revised: January 07, 2010

Accepted: January 07, 2010

(C) Villaverde et al.; Licensee Bentham Open.

This is an open access article licensed under the terms of the Creative Commons Attribution Non-Commercial License (http://creativecommons.org/licenses/ by-nc/3.0/) which permits unrestricted, non-commercial use, distribution and reproduction in any medium, provided the work is properly cited. 